\title{
Olmesartan Improves the Formation of Impaired Epcs and Renal Degeneration through Activation of the ACE2/Ang-(1 - 7)/Mas Receptor Axis in Shrs
}

\author{
Noboru Fukuda ${ }^{1,2 *}$, Naohiko Kobayashi ${ }^{3}$, Akihiko Nagase $^{3}$, Ryo Suzuki ${ }^{1}$, Takahiro Ueno ${ }^{1}$, and Toshihiko Ishimitsu ${ }^{3}$ \\ ${ }^{1}$ Division of Nephrology Hypertension and Endocrinology, Department of Medicine, Nihon University School of Medicine, Tokyo, Japan \\ ${ }^{2}$ Advanced Research Institute of the Sciences and Humanities, Nihon University Graduate School, Tokyo, Japan \\ ${ }^{3}$ Department of Cardiology and Nephrology, Dokkyo Medical University School of Medicine, Tochigi, Japan
}

\begin{abstract}
Objective: We investigated the effects of angiotensin II (Ang II) type 1 (AT1) receptor blocker (ARB) olmesartan on impaired endothelial progenitor cells (EPCs) and renal degeneration through angiotensin converting enzyme 2 (ACE2)/ Ang-(1-7)/Mas receptor (MasR) axis in salt-loaded spontaneously hypertensive rats (SHRs).

Methods: Wistar-Kyoto/lzm (WKY) rats and SHR/Izm were salt-loaded. SHRs were treated with vehicle, hydralazine, olmesartan, and olmesartan plus MasR antagonist A779 for 2 weeks. Peripheral blood mononuclear cells were isolated and subjected to flow cytometric analysis to determine the number of circulating EPCs. To evaluate the mechanisms of effects of olmesartan on renal degeneration, we investigated morphological changes and expression of ACE1, ACE2, MasR, VEGF, eNOS, NAD(P)H oxidases, HIF- $1 \alpha$, CTGF and TGF- $\beta 1$ proteins in the kidneys.

Results: In SHRs, olmesartan was found to significantly increase EPC number and improve glomerulosclerosis; effects which were blunted with MasR antagonist A779. Expressions of CD34, P-eNOS, ACE2 and MasR proteins were significantly lower in SHR kidneys than in WKY rats. Olmesartan was found to significantly upregulate decreased expression of these proteins, this was blunted with A779. Expressions of VEGF, ACE1, NAD(P)H oxidases, HIF$1 \alpha$, CTGF and TGF- $\beta 1$ were significantly higher in the kidneys of SHRs than in WKY rats. Olmesartan significantly downregulated their increased expression, an effect which was also blunted with A779.
\end{abstract}

Conclusion: Olmesartan improved impaired EPC formation and renal degeneration through the ACE2/Ang-(17)/MasR axis in salt-loaded SHRs, suggesting that the ACE2/Ang-(1-7)/MasR axis represents a potential target for hypertension.

Keywords: Olmesartan; Endothelial progenitor cell; Angiotensin converting enzyme 2; Angiotensin-(1-7); Mas receptor; Spontaneously hypertensive rat

\section{Introduction}

The Renin-angiotensin (RA) system has been implicated in essential hypertension because of the antihypertensive effects of RA system inhibitors such as angiotensin-converting enzyme (ACE) inhibitors and angiotensin (Ang) II receptor blockers (ARBs). Several lines of evidence have demonstrated the presence of a local RA system that is independent of the circulating RA system [1,2]. The local RA system induces cardiovascular and renal organ damage by cellular proliferation and oxidative stress [3]. Thus RA system inhibitors have protective effects on cardiovascular organs independent of blood pressure reduction by suppression of vascular growth [2], and extracellular matrix formation [4]. In addition, ARBs have improvement effects on impaired endothelial function by Ang II-mediated oxidative stress in hypertension $[5,6]$.

Although cardiovascular risk factors such as hypertension, dyslipidemia, and diabetes mellitus primarily cause vascular injury, including endothelial damage, it is believed that abnormalities in the repair of endothelial damage enhance vascular injury. Endothelial progenitor cells (EPCs) derived from bone marrow represent up to $0.01 \%$ of cells in the peripheral blood. These cells migrate to areas of endothelial damage and repair them, suggesting that EPC dysfunction determines the eventual level of vascular injury [7]. It has been demonstrated that oxidative stress induces endothelial damage by shortening EPC life span and causing EPC dysfunction [8]. We have demonstrated that the formation of EPCs is suppressed in salt-loaded stroke-prone spontaneously hypertensive rats (SHR-SP) with increases in oxidative stress and that treatment with ARBs (losartan, candesartan, and valsartan) improved the suppression of EPC formation $[8,9]$. We further investigated basal EPC functions and the effects of losartan on EPC function in hypertensive patients, and found that it significantly improved impaired EPC function in hypertensive patients [10]. Thus, ARBs apparently improved impaired EPC formation in hypertension. How and where ARB affects EPCs to improve their formation, however, has been unclear.

It has recently been established that angiotensin-(1-7) (Ang-(1-7)), the hepta peptide which is formed from Ang I or Ang II, is an important component of the RA system and that it exerts several biological effects to oppose the effects of Ang II including anti-proliferation, vasodilator actions and anti-fibrosis effects [11]. Ang-(1-7) can interact directly with the AT1 receptor as an AT1 receptor blocker. [12]. Angiotensinconverting enzyme 2 (ACE2) is a rate-limiting forming enzyme of Ang-

*Corresponding author: Noboru Fukuda, MD, PhD, Division of Nephrology, Hypertension and Endocrinology, Department of Medicine, Nihon University School of Medicine, Ooyaguchi-kami 30-1, Itabashi-ku, Tokyo 173-8610, Japan, Tel: 81-3-3972-8111; Fax: 81-3-3972-8666; E-mail: fukuda.noboru@ nihon-u.ac.jp

Received January 16, 2014; Accepted February 11, 2014; Published February 13,2014

Citation: Fukuda N, Kobayashi N, Nagase A, Suzuki R, Ueno T, et al (2014) Olmesartan Improves the Formation of Impaired Epcs and Renal Degeneration through Activation of the ACE2/Ang-(1-7)/Mas Receptor Axis in Shrs. J Hypertens 3: 138. doi:10.4172/2167-1095.1000138

Copyright: (c) 2014 Fukuda N, et al. This is an open-access article distributed under the terms of the Creative Commons Attribution License, which permits unrestricted use, distribution, and reproduction in any medium, provided the original author and source are credited. 
(1-7) [13], and G protein-coupled receptor Mas is a special functional receptor for Ang-(1-7) [14]. Interestingly, Ang-(1-7) has been reported to have potent effects to hematopoietic cells in bone marrow [15]. Moreover, ACE2/Ang-(1-7)/MasR axis has been reported to exert protective effects against damage to organs including the heart [16] and kidney [17]. Zhang et al. [17], demonstrated that infusion of Ang-(1-7) reduces glomerulosclerosis by counteracting Ang II in experimental glomerulonephritis, suggesting that Ang-(1-7) is also relevant for modulating renal fibrosis in disease states. These organ protective effects of Ang-(1-7) are mediated by MasR. Mas-deficient mice have been shown to exhibit an impairment of heart function associated with changes in collagen expression toward a profibrotic profile [18].

It has been reported that ARBs increased vascular ACE2 and Ang(1-7) to improve vascular remodeling in spontaneously hypertensive rats (SHRs) [19]. Thus improvements of suppressed EPC formation and the protective effects of ARBs against cardiovascular and renal organ damage are possibly mediated by stimulation of the ACE2/Ang-(1-7)/ MasR axis in hypertension. This study was undertaken to investigate the effects of olmesartan on impaired EPCs and renal degeneration through the (ACE2)/Ang-(1-7)/MasR axis in salt-loaded SHRs.

\section{Methods}

\section{Experimental design}

This study conformed to the Guide for the Care and Use of Laboratory Animals published by the US National Institutes of Health (NIH Publication No. 85-23, revised 1996). Ten-week-old male Wistar-Kyoto/Izm (WKY) rats and SHRs, which are provided by the Disease Model Cooperative Research Association (DMCRA, Kyoto, Japan), were purchased Japan SLC, Inc. (Hamamatsu, Japan). All rats were housed in an animal facility with a $12 \mathrm{~h}$ light-dark cycle and were given standard chow and water ad libitum. Systolic blood pressure was measured by the tail-cuff method at the start of 12 weeks of age and at 1-week intervals thereafter. At the age 12 weeks, WKY rats and SHRs received a high-salt diet $(8 \% \mathrm{NaCl})$ for 2 weeks. Salt-loaded SHRs were randomly divided into 4 groups: rats treated with vehicle (SHR-V, $\mathrm{n}=9)$, rats treated with hydralazine $(120 \mathrm{mg} / \mathrm{l}$, drinking water; SHR-H, $\mathrm{n}=8$ ), rats treated with olmesartan medoxomil (Daiichi Sankyo, 0.5 $\mathrm{mg} / \mathrm{kg}$ per day PO; SHR-O, $\mathrm{n}=8$ ), and rats treated with olmesartan medoxomil and MasR antagonist A779 $(0.5 \mathrm{mg} / \mathrm{kg}$ per day PO; SHR$\mathrm{OA}, \mathrm{n}=7$ ) for 2 weeks.

\section{Measurement of circulating EPCs by FACS}

The number of circulating EPCs in peripheral blood was determined using a cell surface antigen as previously described [20]. Circulating mononuclear cells (MNCs) with double CD34 $/ \mathrm{Flk}^{+}$ were quantified as EPCs, which was determined by a fluorescenceactivated cell sorter (FACS; Becton-Dickinson, New York, New York, USA) analysis. Peripheral blood was drawn and MNCs were isolated by the density-gradient centrifuge method. MNCs were stained with a fluorescein isothiocyanate (FITC)-conjugated anti-CD34 monoclonal antibody (Becton-Dickinson, San Jose, USA), and phycoerythrinconjugated anti-Flk1 (R\&D Systems, Minneapolis, Minnesota, USA) respectively. After appropriate gating, the number of $\mathrm{CD} 34^{+} / \mathrm{Flk1} 1^{+}$cells with low cytoplasmic granularity (low sideward scatter) was quantified and expressed as the number of cells per $10^{4}$ total events.

\section{Renal morphology and glomerulosclerosis injury score (GIS)}

After the right kidney sections were stained with hematoxylin and eosin (HE) and periodic acid-Schiff (PAS), glomerulosclerosis in renal cortex was scored as described previously [21]. GIS was scored in 100 glomeruli of each section as G0 for normal glomerulus; G1 for mild sclerosis (25\%); G2 for moderate segmental sclerosis (25\% to $50 \%$ ); G3 for severe segmental sclerosis ( $50 \%$ to $75 \%$ ); and G4 for global sclerosis.

\section{Renal interstitial fibrosis}

The right kidney was excised and immersed in neutralized formalin for histological examination. The area of fibrotic lesions in the interstitium (fibrosis area) of the renal cortex was determined on sections stained by Masson's trichrome method to stain collagen fibers (stained blue), using a computer-aided manipulator program.

\section{Western blot analysis}

CD34, VEGF, ACE1, ACE2, MasR, NAD(P)H oxidase p22 phox, p47 $7^{\text {phox }}$, gp91 $1^{\text {phox }}$, HIF-1 $\alpha$, CTGF, and TGF- $\beta 1$ protein expressions were measured. The renal cortex was homogenized $(25 \% \mathrm{wt} / \mathrm{vol})$ in 10 $\mathrm{mmol} / \mathrm{l} \mathrm{HEPES}$ buffer, $\mathrm{pH} 7.4$, containing $320 \mathrm{mmol} / \mathrm{l}$ sucrose, $1 \mathrm{mmol} / \mathrm{l}$ EDTA, $1 \mathrm{mmol} / \mathrm{l} \mathrm{DTT}, 10 \mu \mathrm{g} / \mathrm{ml}$ leupeptin, and $2 \mu \mathrm{g} / \mathrm{ml}$ aprotinin at $0^{\circ} \mathrm{C}-4^{\circ} \mathrm{C}$ with a polytron homogenizer. Protein concentrations were determined with bovine serum albumin as a standard protein. Equal amounts of protein were loaded in each lane of SDS-PAGE using 13\% gels. The proteins in the gels were transferred electrophoretically to PVDF sheets for $1 \mathrm{~h}$ at $2 \mathrm{~mA} / \mathrm{cm}^{2}$. The sheets were immunoblotted with anti-CD34, anti-VEGF, anti-ACE1, anti-ACE2, anti-MasR, antiNAD $(\mathrm{P}) \mathrm{H}$ oxidase subunits, anti-HIF- $1 \alpha$, anti-CTGF, and anti-TGF- $\beta 1$ antibody (Santa Cruz Biotechnology, Inc., Santa Cruz, California, USA) in a buffer containing $10 \mathrm{mmol} / \mathrm{l}$ Tris- $\mathrm{HCl}, \mathrm{pH} 7.5,100 \mathrm{mmol} / \mathrm{l}$ $\mathrm{NaCl}, 0.1 \%$ Tween 20 , and $5 \%$ skim milk. The proteins transferred to the sheets were detected using the ECL immunoblotting detection system (Amersham-GE Healthcare Life Sciences, Tokyo, Japan). eNOS phosphorylation (P-eNOS) was measured as previously detailed [7].

\section{Statistical Analysis}

All of the values are expressed as mean \pm SEM. Mean values were compared between the 5 groups by ANOVA and the Bonferroni post hoc test for multiple comparisons. $\mathrm{P}<0.05$ was considered statistically significant.

\section{Results}

\section{Effects of olmesartan with MasR antagonist on blood pressure}

Figure 1 shows changes in systolic blood pressure (SBP) in saltloaded WKY rats and SHRs treated with olmesartan plus A779 or hydralazine for 2 weeks. SBP was significantly higher in $(\mathrm{P}<0.01)$ saltloaded SHRs (SHR-V) compared to salt-loaded WKY rats. Treatment with olmesartan (SHR-O) or hydralazine (SHR-H) prevented the increases in SBP in salt-loaded SHRs, resulting in significantly lower $(\mathrm{P}<0.01)$ SBP levels than were measured in rats that received no drug. Rats that received olmesartan or hydralazine for 2 weeks had similar levels of SBP. The levels of SBP were significantly higher $(\mathrm{P}<0.05)$ in SHRs treated with olmesartan plus A779 (SHR-OA) than in rats treated with olmesartan alone (SHR-O) (Figure 1).

\section{Effects of olmesartan with MasR antagonist on EPC number}

Figure 2 shows FACS analyses for CD34 and Flk1 positive cells (EPC number) in salt-loaded WKY rats and in salt-loaded SHRs treated with olmesartan plus A779 or hydralazine for 2 weeks. EPC number was significantly lower $(P<0.01)$ in salt-loaded SHRs $($ SHR-V) than in salt-loaded WKY rats. Treatment with olmesartan (SHR-O), 


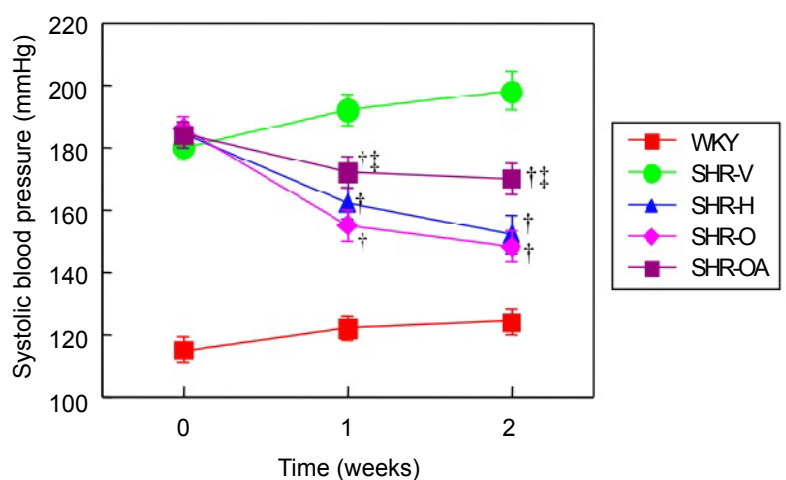

Figure 1: Changes in systolic blood pressure in salt-loaded Wistar-Kyoto (WKY) rats and spontaneously hypertensive rats (SHRs) treated with olmesartan plus Mas receptor antagonist A779 or hydralazine. WKY rats and SHRs received a high-salt diet $(8 \% \mathrm{NaCl})$ for 2 weeks. Salt-loaded SHRs were randomly divided into 4 groups: rats treated with vehicle $(S H R-V, n=9)$, rats treated with hydralazine (120 mg/l, drinking water; SHR-H, n=8), rats treated with olmesartan $(0.5 \mathrm{mg} / \mathrm{kg}$ per day $\mathrm{PO}$; SHR-O, $\mathrm{n}=8)$, and rats treated with olmesartan and MasR antagonist A779 (0.5 mg/kg per day PO; SHR-OA, $n=7)$ for 2 weeks. Systolic blood pressure was measured by the tail-cuff method. Data are expressed as mean \pm SEM. $† P<0.01$ vs SHR-V, $\ddagger P<0.05$ vs SHR-O.

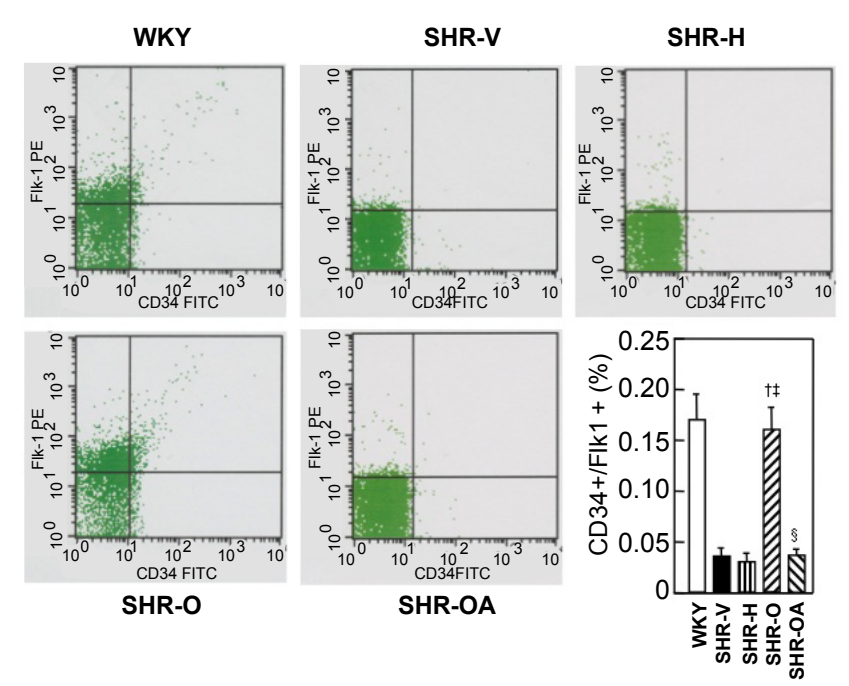

Figure 2: FACS analyses for CD34 and Flk1 positive cells in salt-loaded Wistar-Kyoto (WKY) rats and spontaneously hypertensive rats (SHRs) treated with olmesartan plus Mas receptor antagonist A779 or hydralazine. Salt-loaded SHRs were randomly divided into 4 groups: rats treated with vehicle (SHR-V, $\mathrm{n}=9)$, rats treated with hydralazine $(120 \mathrm{mg} / \mathrm{l}$, drinking water; SHR-H, $\mathrm{n}=8)$, rats treated with olmesartan $(0.5 \mathrm{mg} / \mathrm{kg}$ per day PO; SHR-O, $\mathrm{n}=8)$, and rats treated with olmesartan and MasR antagonist A779 $(0.5 \mathrm{mg} / \mathrm{kg}$ per day PO; SHR$\mathrm{OA}, \mathrm{n}=7$ ) for 2 weeks. Circulating mononuclear cells with CD34+/Flk1+ were quantified as EPCs. Data are expressed as mean \pm SEM. $\dagger P<0.01$ vs SHR-V, $\ddagger P<0.01$ vs SHR-H, $\S P<0.01$ vs SHR-O.

but not hydralazine $($ SHR-H), significantly increased $(P<0.01)$ the EPC number in SHRs. The addition of A779 (SHR-OA) blunted this effect.

\section{Effects of olmesartan with MasR antagonist on renal degeneration}

Morphological effects of olmesartan with or without A779 on glomerulosclerosis and interstitial fibrosis of renal cortex in salt-loaded SHR are shown in Figures 3 and 4, respectively. The renal cortex of salt-loaded SHR (SHR-V) showed severe damage to the glomeruli with sclerotic changes. GIS was significantly higher $(P<0.01)$ in the kidney of salt-loaded SHRs (SHR-V). Treatment with olmesartan (SHR-O), but not hydralazine $($ SHR-H), significantly decreased $(P<0.01)$ GIS, while the addition of $A 779$ resulted in a significant reduction $(\mathrm{P}<0.05)$ of this decrease (SHR-OA) (Figure 3). The renal cortex of salt-loaded SHRs showed interstitial fibrosis. Treatment with olmesartan (SHR-O), but not hydralazine $(\mathrm{SHR}-\mathrm{H})$, significantly $(P<0.01)$ reduced this interstitial fibrosis. Again, A779 significantly $(P<0.05)$ reduced this improvement (SHR-OA) (Figure 4).

\section{Effects of olmesartan with MasR antagonist on endothelial markers}

Expression of CD34 and P-eNOS protein as endothelial markers was significantly lower $(P<0.05)$ in renal cortex from SHRs $(\mathrm{SHR}-\mathrm{V})$ than that from WKY rats. Treatment with olmesartan (SHR-O), but not hydralazine $(\mathrm{SHR}-\mathrm{H})$, significantly upregulated $(P<0.05)$ the decreased expression of CD34 and P-eNOS proteins. The addition of A779 significantly reduced $(P<0.05)$ this upregulated expression (SHR-OA). In contrast, expression of VEGF protein was significantly higher $(P<0.05)$ in renal cortex from salt-loaded SHRs $(S H R-V)$ than that from WKY rats. Treatment with olmesartan (SHR-O), but not hydralazine $($ SHR-H), markedly downregulated $(P<0.05)$ the increased expression of VEGF protein. A779 significantly increased $(P<0.05)$ this downregulated expression of VEGF protein (SHR-OA) (Figure 5).

\section{Effects of olmesartan with MasR antagonist on ACE1, ACE2 and MasR}

Expressions of ACE1 protein was significantly higher $(P<0.05)$ in renal cortex from SHRs (SHR-V) than that from WKY rats. Treatment with olmesartan (SHR-O), but not hydralazine (SHR-H), significantly suppressed $(P<0.05)$ the increased expression of ACE1 protein. A779
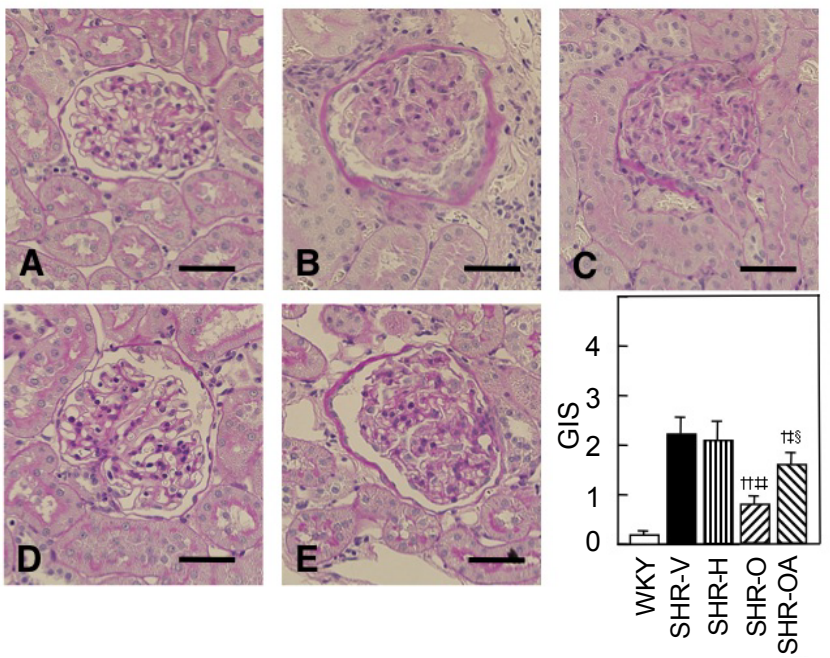

Figure 3: Morphology of glomeruli in kidney from salt-loaded Wistar-Kyoto (WKY) rats and spontaneously hypertensive rats (SHRs) treated with olmesartan plus Mas receptor antagonist A779 or hydralazine. WKY rats and SHRs received a high-salt diet $(8 \% \mathrm{NaCl})$ for 2 weeks. Salt-loaded SHRs were randomly divided into 4 groups: rats treated with vehicle (SHR-V, $n=9)$, rats treated with hydralazine $(120 \mathrm{mg} / \mathrm{l}$, drinking water; $\mathrm{SHR}-\mathrm{H}, \mathrm{n}=8)$, rats treated with olmesartan $(0.5 \mathrm{mg} / \mathrm{kg}$ per day PO; SHR-O, $\mathrm{n}=8)$, and rats treated with olmesartan and MasR antagonist A779 (0.5 mg/kg per day PO; SHR-OA, $n=7)$ for 2 weeks. After the right kidney sections were stained with hematoxylin and eosin and periodic acid-Schiff. Glomerulosclerosis in renal cortex was scored as glomerular injury score (GIS). Data are expressed as mean \pm SEM. $\dagger P<0.05, \dagger+P<0.01$ vs SHR-V, $\ddagger P<0.05, \ddagger \ddagger P<0.01$ vs SHR-H, $\S P<0.05$ vs SHR-O. 

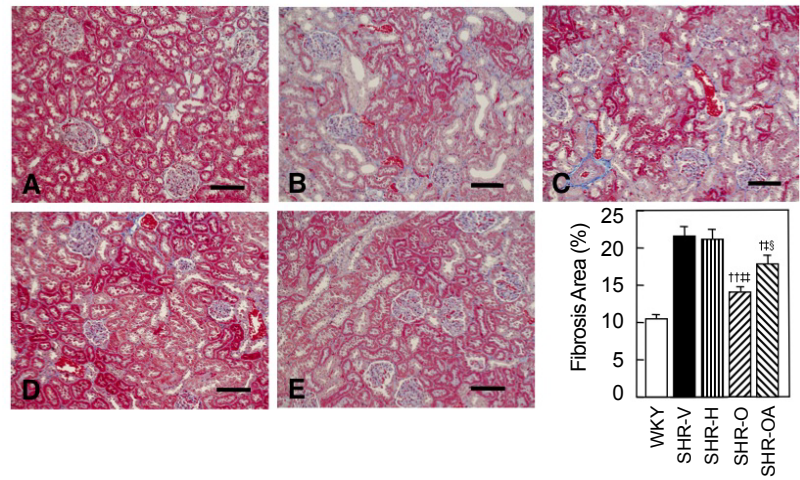

Figure 4: Morphology of interstitium of kidney from salt-loaded Wistar-Kyoto (WKY) rats and spontaneously hypertensive rats (SHRs) treated with olmesartan plus Mas receptor antagonist A779 or hydralazine. WKY rats and SHRs received high-salt diet $(8 \% \mathrm{NaCl})$ for 2 weeks. Salt-loaded SHRs were randomly divided into 4 groups: rats treated with vehicle (SHR-V, $n=9)$, rats treated with hydralazine $(120 \mathrm{mg} / \mathrm{l}$, drinking water; SHR-H, $\mathrm{n}=8)$, rats treated with olmesartan $(0.5 \mathrm{mg} / \mathrm{kg}$ per day PO; SHR-O, $\mathrm{n}=8)$, and rats treated with olmesartan and MasR antagonist A779 (0.5 mg/kg per day PO; SHR-OA, $\mathrm{n}=7)$ for 2 weeks. After the right kidney sections were stained with hematoxylin and eosin and Masson's trichrome method. The area of fibrotic lesions in the interstitium (fibrosis area) of the renal cortex was determined in sections stained by Masson's trichrome method to stain collagen fibers (stained blue), using a computer-aided manipulator program. Data are expressed as mean $\pm \mathrm{SEM}$. $\dagger P<0.05$ $\dagger \dagger P<0.01$ vs SHR-V, $\ddagger P<0.05, \ddagger \ddagger P<0.01$ vs SHR-H, $\S P<0.05$ vs SHR-O.
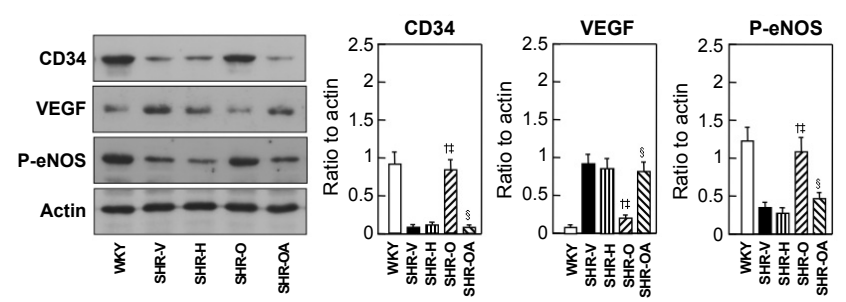

Figure 5: Expression of endothelial markers in kidneys from salt-loaded Wistar-Kyoto (WKY) rats and spontaneously hypertensive rats (SHRs) treated with olmesartan plus MasR antagonist A779 or hydralazine. WKY rats and SHRs received high-salt diet $(8 \% \mathrm{NaCl})$ for 2 weeks. Salt-loaded SHRs were randomly divided into 4 groups: rats treated with vehicle (SHR-V, $n=9)$, rats treated with hydralazine $(120 \mathrm{mg} / \mathrm{l}$, drinking water; $\mathrm{SHR}-\mathrm{H}, \mathrm{n}=8)$, rats treated with olmesartan $(0.5 \mathrm{mg} / \mathrm{kg}$ per day $\mathrm{PO}$; SHR-O, $\mathrm{n}=8)$, and rats treated with olmesartan and MasR antagonist A779 (0.5 mg/kg per day PO; SHR-OA, n=7) for 2 weeks. CD34, VEGF protein expressions and eNOS phosphorylation were measured by Western blot analysis. The ratio of the abundance of each protein to actin was evaluated by densitometric analysis. Data are expressed as mean \pm SEM. $\dagger P<0.05$ vs SHR-V, $\ddagger P<0.05$ vs SHR-H, $\S P<0.05$ vs SHR-O.

significantly increased $(P<0.05)$ this suppressed expression of ACE1 protein (SHR-OA). However, expression of ACE2 and MasR proteins was significantly lower $(P<0.05)$ in the renal cortex of salt-loaded SHRs (SHR-V) than that in that of WKY rats. Treatment with olmesartan (SHR-O), but not hydralazine (SHR-H) significantly upregulated $(P<0.05)$ the increased expression of ACE2 and MasR proteins. A779 significantly decreased $(P<0.05)$ the upregulated expression of ACE2 and MasR protein that followed treatment with olmesartan (SHR-OA) (Figure 6).

\section{Effects of olmesartan with MasR antagonist on NAD(P)H oxidase components}

Expression of $\mathrm{NAD}(\mathrm{P}) \mathrm{H}$ oxidase components p22phox, p47phox
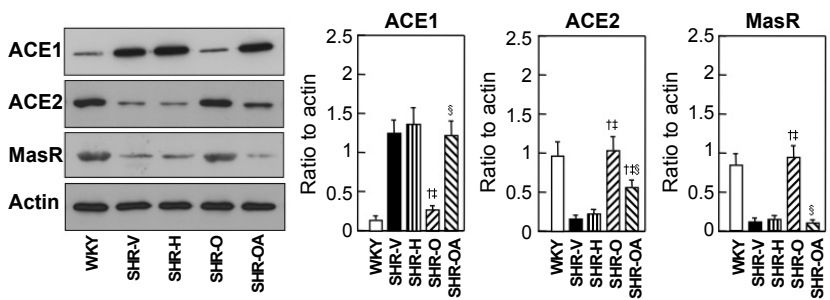

Figure 6: Expression of ACE1, ACE2 and MasR in kidney from Wistar-Kyoto (WKY) rats and spontaneously hypertensive rats (SHRs) treated with olmesartan plus MasR antagonist A779 or hydralazine. WKY rats and SHRs received high-salt diet $(8 \% \mathrm{NaCl})$ for 2 weeks. Salt-loaded SHRs were randomly divided into 4 groups: rats treated with vehicle (SHR-V, $n=9)$, rats treated with hydralazine $(120 \mathrm{mg} / \mathrm{l}$, drinking water; SHR-H, $\mathrm{n}=8)$, rats treated with olmesartan $(0.5$ $\mathrm{mg} / \mathrm{kg}$ per day PO; SHR-O, $\mathrm{n}=8$ ), and rats treated with olmesartan and MasR antagonist A779 (0.5 mg/kg per day PO; SHR-OA, $n=7)$ for 2 weeks. ACE1, ACE2 and MasR protein expressions were measured by Western blot analysis The ratio of the abundance of each protein to actin was evaluated by densitometric analysis. Data are expressed as mean \pm SEM. $\dagger P<0.05$ vs SHR-V $\ddagger P<0.05$ vs SHR-H, $\S P<0.05$ vs SHR-O.

and gp91phox proteins was significantly higher $(P<0.05)$ in renal cortex from salt-loaded SHRs (SHR-V) than that from salt-loaded WKY rats. Treatment with olmesartan (SHR-O), but not hydralazine (SHR-H), significantly downregulated $(P<0.05)$ the increased expression of p22phox, p47phox and gp91phox proteins. A779 significantly increased $(P<0.05)$ this downregulated expression (SHR-OA) (Figure 7).

\section{Effects of olmesartan with MasR antagonist on HIF-1 $\alpha$, CTGF and TGF- $\beta 1$}

Expression of HIF- $1 \alpha$, CTGF and TGF- $\beta 1$ proteins was significantly $(P<0.05)$ higher in renal cortex from SHRs than that from WKY rats. Treatment with olmesartan (SHR-V), but not hydralazine (SHR-H), significantly reduced $(P<0.05)$ the increased expression of HIF-1 $\alpha$, CTGF and TGF- $\beta 1$. A779 significantly increased $(P<0.05)$ this effect (SHR-OA) (Figure 8).

\section{Discussion}

In the present experiments, EPC formation was suppressed in salt-loaded SHRs compared to WKY rats. Olmesartan treatment increased EPC number in SHRs, while the effect was blunted with MasR antagonist A779, indicating that olmesartan stimulates the EPC formation through the ACE2/Ang-(1-7)/MasR axis. At present, all major RA system components have been reported in bone marrow cells such as stromal cells, hematopoietic stem cells and mesenchymal stem cells [21]. It is hypothesized that olmesartan stimulated EPC formation by affecting the local RA system in bone marrow. Ang II has been reported to induce apoptosis and senescence of EPCs through AT1 receptor signaling [22], whereas Ang-(1-7) stimulates the proliferation of CD34 positive EPCs [23]. ARBs have been reported to increase Ang(1-7) through the inhibition of the AT1 receptor that suppresses ACE2forming Ang-(1-7) [24]. Imanishi et al. [25] observed that the number of SHR-derived EPCs from bone marrow was smaller than the number derived from WKY rats. A possible explanation for the suppression of EPC formation is that the Ang II/AT1 receptor axis is enhanced in the bone marrow of SHRs the, while the Ang-(1-7)/MasR axis is impaired.

In the present experiments, olmesartan significantly improved glomerulosclerosis in salt-loaded SHRs, while this effect was inhibited with MasR antagonist A779. It has been established that Ang-(1-7) regulates renal function [26,27]. Ang-(1-7) has been reported to 

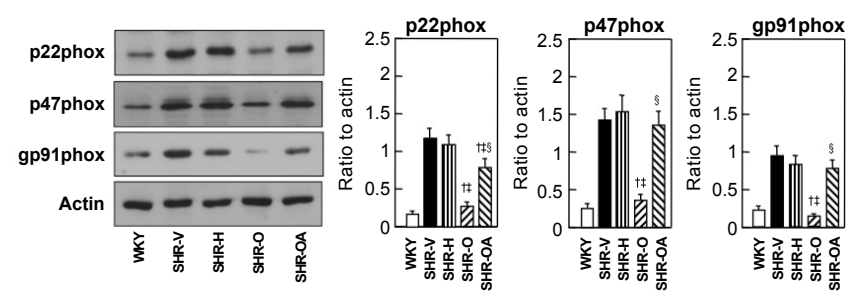

Figure 7: Expression of $\mathrm{NAD}(\mathrm{P}) \mathrm{H}$ oxidases in kidney from salt-loaded Wistar-Kyoto (WKY) rats and spontaneously hypertensive rats (SHRs) treated with olmesartan plus MasR antagonist A779 or hydralazine. WKY rats and SHRs received high-salt diet $(8 \% \mathrm{NaCl})$ for 2 weeks. Salt-loaded SHRs were randomly divided into 4 groups: rats treated with vehicle (SHR-V, $n=9)$, rats treated with hydralazine $(120 \mathrm{mg} / \mathrm{l}$, drinking water; $\mathrm{SHR}-\mathrm{H}, \mathrm{n}=8)$, rats treated with olmesartan $(0.5 \mathrm{mg} / \mathrm{kg}$ per day PO; SHR-O, $\mathrm{n}=8)$, and rats treated with olmesartan and MasR antagonist A779 (0.5 mg/kg per day PO; SHR-OA, n=7) for 2 weeks. Expression levels of p22phox, p47phox and gp91phox proteins ewere measured by Western blot analysis. The ratio of the abundance of each protein to actin was evaluated by densitometric analysis. Data are expressed as mean \pm SEM. $\dagger P<0.05$ vs SHR-V, $\ddagger P<0.05$ vs SHR-H, $\S P<0.05$ vs SHR-O.
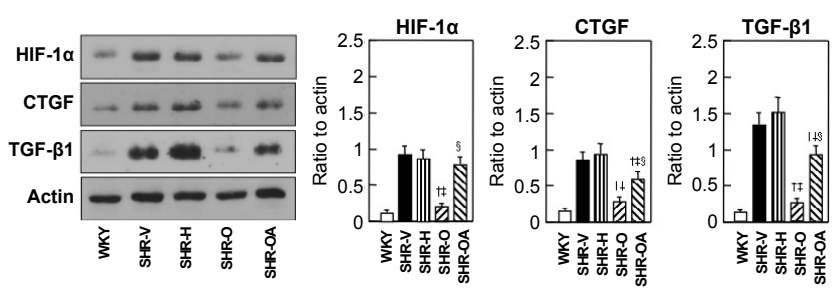

Figure 8: Expression of HIF-1 $\alpha$, CTGF and TGF- $\beta 1$ in kidney from salt-loaded Wistar-Kyoto (WKY) rats and spontaneously hypertensive rats (SHRs) treated with olmesartan plus MasR antagonist A779 or hydralazine. WKY rats and SHRs received high-salt diet $(8 \% \mathrm{NaCl})$ for 2 weeks. Salt-loaded SHRs were randomly divided into 4 groups: rats treated with vehicle (SHR-V, n=9), rats treated with hydralazine $(120 \mathrm{mg} / \mathrm{l}$, drinking water; $\mathrm{SHR}-\mathrm{H}, \mathrm{n}=8)$, rats treated with olmesartan $(0.5 \mathrm{mg} / \mathrm{kg}$ per day $\mathrm{PO}$; $\mathrm{SHR}-\mathrm{O}, \mathrm{n}=8)$, and rats treated with olmesartan and MasR antagonist A779 $(0.5 \mathrm{mg} / \mathrm{kg}$ per day PO; SHR-OA, $\mathrm{n}=7$ ) for 2 weeks. HIF- $1 \alpha$, CTGF and TGF- $\beta 1$ protein expressions were measured by Western blot analysis. The ratio of the abundance of each protein to of actin was evaluated by densitometric analysis. Data are expressed as mean \pm SEM. $\dagger P<0.05$ vs SHR-V, $\ddagger P<0.05$ vs SHR-H, $\S P<0.05$ vs SHR-O

present in proximal tubules and exists in urine at higher concentrations than Ang II [26]. Chappell et al. [27] demonstrated co-localization of ACE2 and Ang-(1-7) in renal tubules, indicating the direct conversion of Ang II to Ang-(1-7) in the kidney. Moreover, ACE inhibitors and ARBs stimulate the intrarenal formation of Ang-(1-7) converted from Ang II by ACE2 [28]. In the present experiments, expression of ACE1 protein was upregulated, whereas expression of ACE2 and MasR proteins was downregulated in kidney from SHRs in comparison to WKY rats, indicating enhanced ACE1/Ang II/AT1 receptor axis and impaired ACE2/Ang-(1-7)/MasR axis in the kidney from salt-loaded SHRs. Olmesartan treatment upregulated the decreased expression of ACE2 and MasR proteins. A779 significantly reduced the upregulated expression of these proteins by olmesartan. Agata et al. [16], also demonstrated that ARB increases endogenous Ang-(1-7) through the overexpression of ACE2. It is possible that olmesartan upregulated the impaired ACE2/Ang-(1-7)/MasR axis that counteracted the enhanced Ang II/AT1 receptor axis, by which the renal degeneration was improved in the salt-loaded SHRs.

In the present experiments, expression of $\mathrm{NAD}(\mathrm{P}) \mathrm{H}$ oxidase components was enhanced in kidney from salt-loaded SHRs. Recently Lo et al. [29], demonstrated that Ang II-induced activation of NAD(P)
$\mathrm{H}$ oxidase and generation of superoxide in the heart, kidney and blood vessels were blunted by infusion of recombinant human ACE2, in association with a lowering of plasma Ang II and elevation of Ang(1-7) levels in WKY rats. In SHRs, infusion of recombinant human ACE2 suppressed the hypertension and $\mathrm{NAD}(\mathrm{P}) \mathrm{H}$ oxidase activation and the increased superoxide generation in the heart, kidney and blood vessels, indicating that ACE2 is a negative regulator for blood pressure and $\mathrm{NAD}(\mathrm{P}) \mathrm{H}$ oxidase activation in hypertension [29]. Olmesartan treatment suppressed the enhanced expression of $\mathrm{NAD}(\mathrm{P}) \mathrm{H}$ oxidase components that was inhibited with MasR antagonist A779. These findings indicate that olmesartan inhibits intrarenal Ang II-enhanced $\mathrm{NAD}(\mathrm{P}) \mathrm{H}$ oxidase to improve renal degeneration through the ACE2/ Ang-(1-7)/MasR axis.

We further investigated mechanisms underlying the olmesartaninduced improvement of renal degeneration by the activation of the ACE2/Ang-(1-7)/MasR axis. Expression of CD34 and P-eNOS proteins was lower in kidney from SHR. CD34 and P-eNOS are markers for endothelial functions [30]. P-eNOS was reported to be impaired in kidney from diabetic rats [31]. Olmesartan treatment upregulated the decreased expression of these proteins, which was blunted with A779. These findings indicate impaired glomerular endothelial function in kidney from salt-loaded SHRs. Olmesartan treatment increased the suppressed endothelialized factors through the activation of the ACE2/ Ang-(1-7)/MasR axis. Contrarily, expression of VEGF and HIF-1a as ischemia response factors was significantly higher in kidney from SHRs than that from WKY rats. Olmesartan treatment significantly downregulated the increases expression of VEGF and HIF-1 $\alpha$ which was inhibited with MasR antagonist A779. VEGF and HIF-1 $\alpha$ are molecules that induce endothelialization in response to ischemia. These proteins might be upregulated against ischemia of the kidney in salt-loaded SHRs.

The enhanced intrarenal RA system is associated with renal damage, such as interstitial fibrosis and tubular degeneration, through activation of TGF- $\beta 1$ [32]. The activated TGF- $\beta 1$ directly stimulates synthesis of extra cellular matrix components, reduces collagenase production, and induces profibrogenic factor CTGF [33]. In the kidney, TGF- $\beta$ induces epithelial-mesenchymal transformation in nephrotubules with an accumulation of myofibroblasts and subsequent tubular atrophy, key determinants of renal fibrosis in chronic renal injury [34]. Thus, renal degeneration in kidney from hypertensive rats is induced by the intrarenal Ang II with stimulation of TGF- $\beta 1$, which can be suppressed by ARBs [35]. In the present experiments, kidney from salt-loaded SHRs showed interstitial fibrosis, tubular atrophy, necrosis and cast formation. Treatment with olmesartan significantly improved this degeneration where expression of CTGF and TGF- $\beta 1$ was higher than in WKY rats. Olmesartan downregulated the increases expression of these proteins that were inhibited by MasR antagonist A779, indicating that olmesartan improves renal degeneration by suppressing renal Ang II induced CTGF and TGF- $\beta 1$ through the activation of the ACE2/ Ang-(1-7)/MasR axis.

In conclusion, salt-loaded SHRs showed suppressed EPC formation and renal degeneration with decreases in expression of CD34 and $\mathrm{P}-\mathrm{eNOS}$ and increases in expression of $\mathrm{NAD}(\mathrm{P}) \mathrm{H}$ oxidases, HIF- $1 \alpha$, VEGF, CTGF and TGF- $\beta 1$. Olmesartan treatment improved impaired EPC formation and renal degeneration through the ACE2/Ang-(1-7)/ MasR axis in salt-loaded SHRs, suggesting that the ACE2/Ang-(1-7)/ MasR axis represents a potential target for hypertension. 
Citation: Fukuda N, Kobayashi N, Nagase A, Suzuki R, Ueno T, et al. (2014) Olmesartan Improves the Formation of Impaired Epcs and Renal Degeneration through Activation of the ACE2/Ang-(1-7)/Mas Receptor Axis in Shrs. J Hypertens 3: 138. doi:10.4172/2167-1095.1000138

\section{Acknowledgement}

This work was supported in part by a Grant-in-Aid for the Nihon University Multidisciplinary Research Grant from 2011 to 2013. We thank Yasuko Mamada Keiko Fukuda, Hisato Hirata, Yoshifumi Machida, Noriko Suzuki, Fumie Yokotsuka, Kyoko Tabei, and Machiko Sakata for technical assistance.

\section{References}

1. Ampbell DJ, Habener JF (1986) Angiotensinogen gene is expressed and differentially regulated in multiple tissues of the rat. J Clin Invest 78: 31-39.

2. Fukuda N, Satoh C, Hu WY, Soma M, Kubo A, et al. (1999) Production of angiotensin II by homogeneous cultures of vascular smooth muscle cells from spontaneously hypertensive rats. Arterioscler Thromb Vasc Biol 19: 1210-1217.

3. Rueckschloss U, Quinn MT, Hotz J, Morawietz H (2002) Dose-dependent regulation of $\mathrm{NAD}(\mathrm{P}) \mathrm{H}$ oxidase expression by angiotensin II in human endothelial cells. Protective effect of angiotensin II type 1 receptor blockade in patients with coronary artery disease. Arterioscler Thromb Vasc Biol 22: 1845-1851.

4. Wassmann S, Nickenig G (2006) Pathophysiological regulation of the AT1 receptor and implications for vascular disease. J Hypertens Suppl 24: S15-21.

5. Berry C, Brosnan MJ, Fennell J, Hamilton CA, Dominiczak AF (2001) Oxidative stress and vascular damage in hypertension. Curr Opin Nephrol Hypertens 10 247-255.

6. Desideri G, Bravi MC, Tucci M, Croce G, Marinucci MC, et al. (2003) Angiotensin II inhibits endothelial cell motility through an AT1-dependent oxidant-sensitive decrement of nitric oxide availability. Arterioscler Thromb Vasc Biol 23: 12181223.

7. Yao EH, Fukuda N, Matsumoto T, Kobayashi N, Katakawa M, et al. (2007) Losartan improves the impaired function of endothelial progenitor cells in hypertension via an antioxidant effect. Hypertens Res 30: 1119-1128.

8. Yao EH, Yu Y, Fukuda N (2006) Oxidative stress on progenitor and stem cells in cardiovascular diseases. Curr Pharm Biotechnol 7: 101-108.

9. Yu Y, Fukuda N, Yao EH, Matsumoto T, Kobayashi N, et al. (2008) Effects of an ARB on endothelial progenitor cell function and cardiovascular oxidation in hypertension. Am J Hypertens 21: 72-77.

10. Suzuki R1, Fukuda N, Katakawa M, Tsunemi A, Tahira Y, et al. (2013) Effects of an Angiotensin II Receptor Blocker on the Impaired Function of Endothelial Progenitor Cells in Patients With Essential Hypertension. Am J Hypertens.

11. lusuf D, Henning RH, van Gilst WH, Roks AJ (2008) Angiotensin-(1-7) pharmacological properties and pharmacotherapeutic perspectives. Eur $J$ Pharmacol 585: 303-312.

12. Clark MA, Diz DI, Tallant EA (2001) Angiotensin-(1-7) downregulates the angiotensin II type 1 receptor in vascular smooth muscle cells. Hypertension 37: 1141-1146.

13. Donoghue M, Hsieh F, Baronas E, Godbout K, Gosselin M, et al. (2000) A nove angiotensin-converting enzyme-related carboxypeptidase (ACE2) converts angiotensin I to angiotensin 1-9. Circ Res 87: E1-9.

14. Santos RA, Simoes e Silva AC, Maric C, Silva DM, Machado RP, et al. (2003) Angiotensin-(1-7) is an endogenous ligand for the $G$ protein-coupled receptor Mas. Proc Natl Acad Sci U S A 100: 8258-8263.

15. Heringer-Walther S, Eckert K, Schumacher SM, Uharek L, Wulf-Goldenberg A et al. (2009) Angiotensin-(1-7) stimulates hematopoietic progenitor cells in vitro and in vivo. Haematologica 94: 857-860.

16. Agata J, Ura N, Yoshida H, Shinshi Y, Sasaki H, et al. (2006) Olmesartan is an angiotensin II receptor blocker with an inhibitory effect on angiotensinconverting enzyme. Hypertens Res 29: 865-874.

17. Zhang J, Noble NA, Border WA, Huang Y (2010) Infusion of angiotensin-(1-7) reduces glomerulosclerosis through counteracting angiotensin II in experimental glomerulonephritis. Am J Physiol Renal Physiol 298: F579-F588.

18. Santos RA, Castro CH, Gava E, Pinheiro SV, Almeida AP, et al. (2006) Impairment of in vitro and in vivo heart function in angiotensin-(1-7) receptor MAS knockout mice. Hypertension 47: 996-1002.

19. Igase M, Kohara K, Nagai T, Miki T, Ferrario CM (2008) Increased expression of angiotensin converting enzyme 2 in conjunction with reduction of neointima by angiotensin II type 1 receptor blockade. Hypertens Res 31: 553-559.

20. Santhanam AV, Smith LA, Akiyama M, Rosales AG, Bailey KR, et al. (2005)
Role of endothelial NO synthase phosphorylation in cerebrovascular protective effect of recombinant erythropoietin during subarachnoid hemorrhage-induced cerebral vasospasm. Stroke 36: 2731-2737.

21. Matsuda H, Fukuda N, Ueno T, Katakawa M, Wang X, et al. (2011) Transcriptiona inhibition of progressive renal disease by gene silencing pyrrole-imidazole polyamide targeting of the transforming growth factor- $-^{2} 1$ promoter. Kidney Int 79: $46-56$

22. Endtmann C, Ebrahimian T, Czech T, Arfa O, Laufs U, et al. (2011) Angiotensin II impairs endothelial progenitor cell number and function in vitro and in vivo: implications for vascular regeneration. Hypertension 58: 394-403.

23. Heringer-Walther S, Eckert K, Schumacher SM, Uharek L, Wulf-Goldenberg A et al. (2009) Angiotensin-(1-7) stimulates hematopoietic progenitor cells in vitro and in vivo. Haematologica 94: 857-860.

24. Gallagher PE, Chappell MC, Ferrario CM, Tallant EA (2006) Distinct roles for ANG II and ANG-(1-7) in the regulation of angiotensin-converting enzyme 2 in rat astrocytes. Am J Physiol Cell Physiol 290: C420-426.

25. Imanishi T, Kobayashi K, Hano T, Nishio I (2005) Effect of estrogen on differentiation and senescence in endothelial progenitor cells derived from bone marrow in spontaneously hypertensive rats. Hypertens Res 28: 763-772.

26. Chappell MC, Allred AJ, Ferrario CM (2001) Pathways of angiotensin-(1-7) metabolism in the kidney. Nephrol Dial Transplant 16: 22-26.

27. Chappell MC, Modrall JG, Diz DI, Ferrario CM (2004) Novel aspects of the renal renin-angiotensin system: angiotensin-(1-7), ACE2 and blood pressure regulation. Contrib Nephrol 143: 77-89.

28. Ferrario CM, Jessup J, Gallagher PE, Averill DB, Brosnihan KB, et al. (2005) Effects of renin-angiotensin system blockade on renal angiotensin-(1-7) forming enzymes and receptors. Kidney Int 68: 2189-2196

29. Lo J, Patel VB, Wang Z, Levasseur J, Kaufman S, et al. (2013) Angiotensinconverting enzyme 2 antagonizes angiotensin II-induced pressor response and NADPH oxidase activation in Wistar-Kyoto rats and spontaneously hypertensive rats. Exp Physiol 98: 109-122.

30. Metsuyanim S, Harari-Steinberg O, Buzhor E, Omer D, Pode-Shakked N, et al (2009) Expression of stem cell markers in the human fetal kidney. PLoS One 4: e6709.

31. Cheng $H$, Wang $H$, Fan X, Paueksakon P, Harris RC (2012) Improvement of endothelial nitric oxide synthase activity retards the progression of diabetic nephropathy in db/db mice. Kidney Int 82: 1176-1183.

32. Kobori H, Nangaku M, Navar LG, Nishiyama A (2007) Theintrarenal reninangiotensin system: from physiology to the pathobiology of hypertension and kidney disease. Pharmacol Rev 59: 251-287.

33. Gore-Hyer E, Shegogue D, Markiewicz M, Lo S, Hazen-Martin D, et al. (2002) TGF-beta and CTGF have overlapping and distinct fibrogenic effects on human renal cells. Am J Physiol Renal Physiol 283: F707-716.

34. Zeisberg M, Hanai J, Sugimoto $H$, Mammoto T, Charytan D, et al. (2003) BMP7 counteracts TGF-beta1-induced epithelial-to-mesenchymal transition and reverses chronic renal injury. Nat Med 9: 964-968.

35. Song JH, Cha SH, Hong SB, Kim DH (2006) Dual blockade of the reninangiotensin system with angiotensin-converting enzyme inhibitors and angiotensin II receptor blockers in chronic kidney disease. J Hypertens Supp 24: S101-106. 